\title{
EfFective Factors on continued USE OF THE Picture Archiving AND Communication System in Teaching Hospitals of Shiraz University of Medical SCIENCES
}

\author{
Mojtaba Kafashi ${ }^{*}$, Mohtaram Nematollahi2
}

${ }^{1}$ School of Management and Information Sciences, Shiraz University of Medical Sciences, Shiraz, Iran.

${ }^{2}$ Associate Professor, Anesthesiology and Critical Care Research Center, Shiraz University of Medical Sciences, Shiraz, Iran.

\begin{tabular}{|c|c|}
\hline Article Info & A B S T R A C T \\
\hline Article type: & \multirow{4}{*}{$\begin{array}{l}\text { Introduction: } \\
\text { The evaluation of information systems by health care professionals is one } \\
\text { of the key factors for improving the acceptability and usability of systems. } \\
\text { Picture Archiving and Communication System (PACS) is the support for } \\
\text { more accurate diagnosis in the medical field. Therefore, the present study } \\
\text { aimed to determine the factors affecting the continuance of this system. } \\
\text { Material and Methods: } \\
\text { This is a descriptive-analytic cross-sectional study conducted in 2014. The } \\
\text { sample consisted of } 200 \text { PACS users (general practitioners, residents, } \\
\text { specialists and radiologists) in Faghihi and Nemazee hospitals of Shiraz } \\
\text { which selected by stratified random sampling. Data were collected using a } \\
\text { researcher-made questionnaire. To confirm the reliability of the } \\
\text { questionnaire, the Cronbach's alpha coefficient (84\%) was used and } 5 \\
\text { experts from health information management were used to confirm the } \\
\text { validity of the questionnaire. The data were analyzed using descriptive and } \\
\text { inferential statistics. }\end{array}$} \\
\hline & \\
\hline $\begin{array}{l}\text { Article History: } \\
\text { Received: } 2018-10-10 \\
\text { Revised: } 2018-10-25 \\
\text { Accepted: } 2018-11-05\end{array}$ & \\
\hline $\begin{array}{l}\text { * Corresponding author: } \\
\text { Mojtaba Kafashi } \\
\text { School of Management and } \\
\text { Information Sciences, Shiraz } \\
\text { University of Medical Sciences, } \\
\text { Shiraz, Iran. } \\
\text { Email: kafashim@gmail.com }\end{array}$ & \\
\hline
\end{tabular}

\section{Results:}

The study showed that in selected hospitals according to the model, the highest correlation was found between the relationship between expectation confirmation of and satisfaction ( $r=0.682$; $R 2=0.465)$ and the least correlation was related to the relationship between the expectation confirmation and the compatibility ( $\mathrm{r}=0.347$; $\mathrm{R} 2=0.120)$. Also, there was a significant relationship between the level of education of users and the continuance intention to use the PACS system $(\mathrm{P}=0.008)$. Radiologists have the highest tendency to continue using the PACS system and the leastfavored were specialists.

\section{Conclusion:}

The results indicated that for continued use of information systems by users and increase their satisfaction and the success of systems, consideration of users' expectations, requirements and technical requirements of systems to fit the system with the tasks of users before implementing information systems is necessary and inevitable.

Keywords:

Picture Archiving and Communication System (PACS), Continued Use, Satisfaction

How to cite this paper

Kafashi M, Nematollahi M. Effective Factors on continued use of the Picture Archiving and Communication System in Teaching Hospitals of Shiraz University of Medical Sciences. Front Health Inform. 2019; 8(1): e1. DOI: 10.30699/fhi.v8i1.160

\section{INTRODUCTION}

Although the adoption and use of intelligence systems is essential in their success, the long-term credibility of these systems depends on the continued use of them-as opposed to initial use [1]]. In addition, with the prolonged use of information systems, users' behavioral performance becomes more complicated than their initial performance []․ 
As a result, it is important to review the users' behavior about the continued use of information systems over time [ $\underline{3}$ ]. The continuance intention to use the information system is one of the most important indicators in the implementation, success and continued use of the long-term information system [1]. The inability or lack of continuance intention to use the information system reflects the poor system's usability [4]. Evaluation of information systems at different stages of development and its normal use is one of the key factors for improving the acceptability and usability of systems by health care professionals [ $\underline{5}]$.

In today's medicine, imaging is one of the main methods for diagnosis, and improving quality, reducing costs and protecting their records will have a perceptible impact on the overall performance of a healthcare system.

For the first time in 1982 at the IEEE Medical Imaging Conference, a system was introduced that could store, display and transmit images and other information, called the Picture Archiving and Communication System (PACS). PACS is an electronic system for the management of hospital images []].

The initial acceptance of electronic health systems does not guarantee the benefits of these systems (such as improving care and reducing costs) []]. Studies have shown that if the information system does not meet the needs of users, then the system will be released even if its initial acceptance has been successful. Therefore, researchers have found that there is a need to understand "the user's continuance intention to use the system" [4]].

Several information technology evaluation models have been proposed that demonstrate the intention of users to behave in a particular system (acceptance models) or their satisfaction from an implemented system or future user behavior (continuance intention to use). Some of them are including theory of planned behavior, information systems success model []], technology acceptance model [9] , unified theory of acceptance and use of technology [10], the expectations confirmation theory and continuance intention to use information system [1].

In this study, we attempt to identify the determinants of the continuance use of the PACS system, which includes both the behavioral intention of users and the system-specific PACS, and measure the relationships between them. The evaluation model used in this study was based on the evaluation of the constructs in the expectation confirmation model [1], the health information technology post-adoption model []ㅡ, and the information system success measurement model [11].

The most important factors affecting the continuance use of the PACS after the combination of the factors of the three models mentioned, is shown in Fig 1, according to which the relationships in the model will be measured.

\section{Expectation Confirmation}

This factor derived from the expectation confirmation model is defined as a range of individual beliefs that meet individual expectations about the performance of a particular information system [1].

\section{User Support}

Accessibility of the system when needed, system help the user to understand and access system data, user education by system []].

\section{System Compatibility}

The use of an information system that meets all aspects of the user's work, the user's habits and behavior, and the organization of the user's work []. Two factors are the user support and compatibility of information systems derived from the Health Information Technology Post-Adoption Model, Palm et al Several studies have also demonstrated the motivational role of user support [12-14] and compatibility [1-17] of information systems in developing the process of accepting and expanding information technology in organizations.

\section{Perceived Usefulness}

This factor, derived from the Expectation Confirmation Model, is defined as a degree that a person considers using a specific system to enhance his performance in the system for which it is designed [18].

\section{Satisfaction}

This factor, derived from the expectation confirmation model, is defined as an emotional state and psychology that is defined by a cognitive measure that is derived from the comparison of performance and expectations [1]].

\section{User Quality}

This factor derives from the information system success measurement model. The user quality is meant by the capabilities of the users that are related to the acceptance and better use of the technology, such as information abilities and capabilities, interest and motivation, and training [19].

\section{Continuance Intention to Use}

Bhattacherjee in 2001 defines the continuance intention of information systems in the expectation 
confirmation theory as an individual's intention for continued use of an information system (in contrast to the use or initial acceptance). The continuance intention has a solid correlation with the actual continued use of the information system [1] .

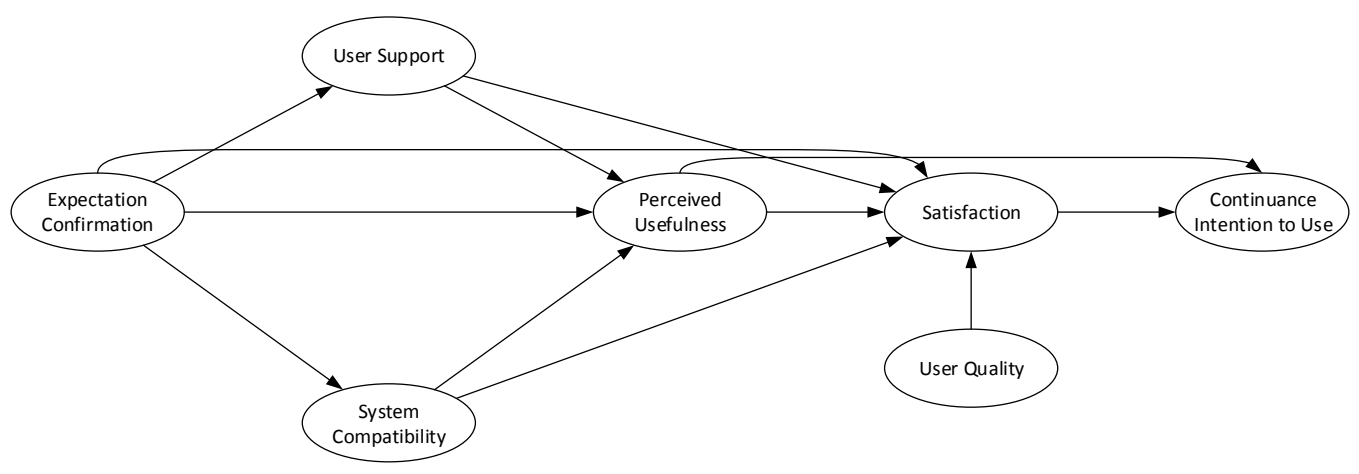

Fig 1: Factors affecting the continuance use of the PACS system

\section{MATERIALS AND METHODS}

This descriptive-analytic study was conducted in 2014. The research community consisted of PACS users (general practitioners, residents, specialists and radiologists) in Faghihi and Nemazee hospitals of Shiraz. The sample consisted of 200 PACS users who were selected by stratified random sampling.

The data gathering tool was a researcher-made questionnaire that was used to measure the factors affecting the continued use of the PACS system among users. The content validity of the questionnaire was evaluated by 5 health information management experts (managers and professors of health information technology and medical informatics teaching groups).

The questionnaire consisted of 33 questions of 5 options, which included 7 constructs of expectation confirmation including 5 questions from the standard questionnaire of the Bhattacherjee's expectation confirmation model [1], the user support including 6 questions from the Health Information Technology Post-Adoption Model, Palm et al, The compatibility included 6 questions from the health information technology post-adoption model [], perceived usefulness including 5 questions from the standard questionnaire of the Bhattacherjee's expectation confirmation model [1], user quality including 3 questions from the information system success measurement model questionnaire [19], satisfaction consists of 3 questions from the standard questionnaire of the Bhattacherjee's expectation confirmation model [1] and the continuance intention to use include 5 questions from the standard questionnaire of the Bhattacherjee's expectation confirmation model [1]. The questions were in closed format with five points Likert scale (totally agree, agree, don't mind, disagree, and totally disagree).

Reliability of the questionnaire was calculated using
Cronbach's alpha coefficient ( $\alpha=0.84)$. The data were analyzed using descriptive statistics (frequency, mean and standard deviation) and inferential statistics (Independent t-test, ANOVA, Pearson correlation coefficient and regression) and analyzed by SPSS 22 software.

\section{RESULTS}

Out of the 179 respondents, $60.9 \%$ were male and $39.1 \%$ were female. More than $90 \%$ of respondents were under the age of 40 . Also, the majority of them were residents (37.4\%). $48 \%$ of respondents with a work history of less than 2 years were related to the PACS system. Only $36.9 \%$ of the respondents participated in the PACS system training prior to the implementation of the system, and $64.8 \%$ of them did not consider the previous training of the PACS system useful.

Table 1 shows the mean and standard deviation of the main variables of the research. The quality of the user with an average of 14.4 and the compatibility of the PACS system with an average of 3.61 was the lowest average scores from the viewpoint of PACS users in Faghihi and Nemazee hospitals of Shiraz.

Fig 2 shows the correlation between the main variables of research in the research community. According to Fig 2, the existence of a direct and positive relationship between all relationships is confirmed at a significant level of 0.01 , with the highest correlation between the relationship between the expectation confirmation and satisfaction ( $\left.\mathrm{r}=0.682 ; \mathrm{R}^{2}=0.465\right)$ and the lowest correlation between the expectation confirmation and compatibility $\left(\mathrm{r}=0.347 ; \quad \mathrm{R}^{2}=0.120\right)$. The satisfaction's effect on the continuance intention to use PACS system, from the point of view of users, was more than their perceived usefulness of the system. Also, among the factors affecting user satisfaction, the PACS system compatibility had the 
least effect (All P-values <0.001).

Table 1: Average and standard deviations of the main variables of the research

\begin{tabular}{|l|l|l|}
\hline Main variables & Mean & $\begin{array}{l}\text { Standard } \\
\text { deviation }\end{array}$ \\
\hline Expectation Confirmation & 4.008 & 0.5729 \\
\hline User support & 3.7868 & 0.6226 \\
\hline System Compatibility & 3.6145 & 0.6153 \\
\hline Perceived usefulness & 4.0592 & 0.6574 \\
\hline User Quality & 4.1471 & 0.5965 \\
\hline Satisfaction & 4.0279 & 0.7748 \\
\hline $\begin{array}{l}\text { Continuance intention to } \\
\text { use }\end{array}$ & 3.8358 & 0.6820 \\
\hline
\end{tabular}

Table 2 shows the relationships between demographic variables with satisfaction and the continuance intention to use the PACS system, according to which the relationships between educational level variables (including radiologist, general practitioner, residents and specialist) satisfaction, work history related to the systemSatisfaction and work history related to the systemcontinuance intention to use the PACS system are not significant $(\mathrm{P}>0.05)$, while other relationships are statistically significant $(\mathrm{P}<0 / 05)$.

Based on the findings of the research, the opinions average of radiologists regarding the continued use of the PACS system were equal to 15.4, residents 3.95, general practitioners 3.83 and specialists 3.99 , indicating that radiologists had the highest tendency to continue the PACS system and the specialists had the least tendency.

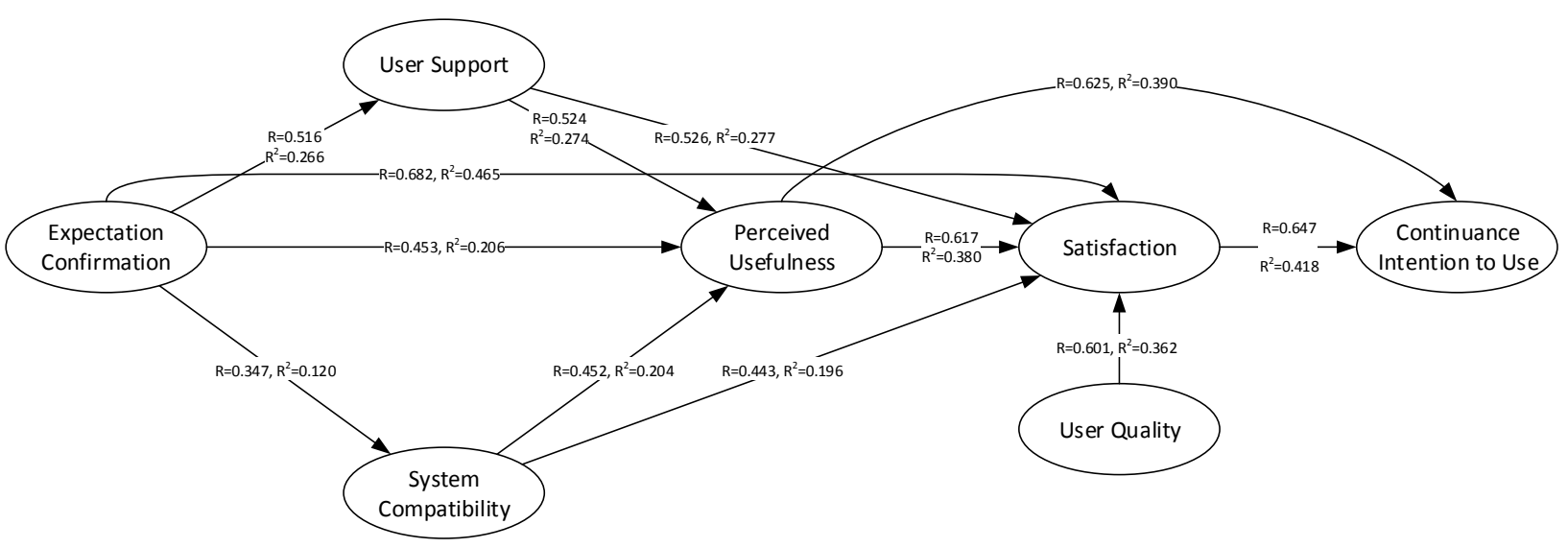

Fig 2: Correlation between main variables of research

Table 2: Relationship between demographic variables with satisfaction and continuance intention to use the PACS system

\begin{tabular}{|l|l|l|l|}
\hline Variables & $\begin{array}{l}\text { Statistical } \\
\text { tests }\end{array}$ & $\begin{array}{l}\text { User } \\
\text { Satisfaction } \\
\text { PACS } \\
\text { (P-Value) }\end{array}$ & $\begin{array}{l}\text { continuance } \\
\text { intention to } \\
\text { PACS use } \\
\text { (P-Value) }\end{array}$ \\
\hline Gender & $\begin{array}{l}\text { Independent } \\
\text { t-test }\end{array}$ & 0.006 & 0.001 \\
\hline Age & ANOVA & 0.092 & 0.087 \\
\hline Education & $\begin{array}{l}\text { Independent } \\
\text { t-test }\end{array}$ & 0.426 & 0.008 \\
\hline Experience & ANOVA & 0.668 & 0.928 \\
\hline $\begin{array}{l}\text { Training } \\
\text { before } \\
\text { using }\end{array}$ & $\begin{array}{l}\text { Independent } \\
\text { t-test }\end{array}$ & 0.0001 & 0.001 \\
\hline $\begin{array}{l}\text { Usefulness } \\
\text { of Training } \\
\text { before } \\
\text { using }\end{array}$ & $\begin{array}{l}\text { Independent } \\
\text { t-test }\end{array}$ & 0.002 & 0.001 \\
\hline
\end{tabular}

\section{DISCUSSION}

The results indicate that there is a significant relationship between user satisfaction and the continuance intention to use the PACS system, which is consistent with the results of Wang [20] , Tabibi et al [21], Hadji et al [22] , Kim [23], Lee [24] , Stone et al [25], and Cheng [르].

Satisfaction of users is a key driver for their willingness to use and adhere to and loyal to the information systems. Satisfaction is one of the important factors in the success of information systems and indicates the efficiency, effectiveness and appropriate productivity of systems.

From the perspective of users, the PACS system has been able to improve the quality of decision-making, increase the accuracy of clinical diagnosis and reduce their workload in comparison with the use of radiology stereotypes, and lead to their willingness to use this system continuously. As the results show, there is a significant relationship between perceived 
confirmation and satisfaction with the PACS system, which is related to Hsieh and Wang [27], Hadji et al

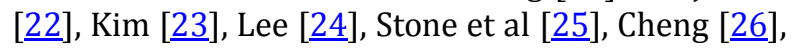
Palm et al [ㅁ], and Koo et al [료].

In the present study, expectation confirmation has the greatest effect on satisfaction. Therefore, the PACS system should be developed in such a way as to meet the initial expectations and user requirements in a satisfactory way, in order to increase satisfaction and subsequently the continuance intention to use the PACS system because, according to Bhattacherjee [1]], the level of user satisfaction Mostly determined based on the extent to which their expectations are confirmed, therefore, system administrators' awareness of user expectations and requirements and the requirements of the system is an important and fundamental issue that should be considered before designing, implementing, and using users of a system.

The results of this study confirm the significant relationship between perceived usefulness and satisfaction with the PACS system, which is consistent with the results of Kulkarni et al [29],

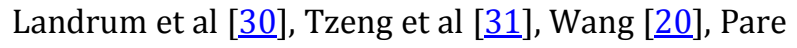
et al [2] , Tabbi et al [21], Hadji et al [2], Lee [24], and Cheng [드].

Most studies have shown that perceived usefulness plays an important role in increasing the satisfaction of users of information systems. In fact, the ability to create and manage appropriate radiology images in the PACS system in an easy way is one of the important benefits of using this system. Clearly, in this case, the PACS system will reduce the workload of physicians and radiologists and add to their level of satisfaction.

As shown, there is a significant relationship between perceived usefulness and the continuance intention to use the PACS system.

The results of studies by Tabibi et al [21], Hsieh et al [27], Hadji et al [22]], Kim [23] , Lee [녀], Stone et al [25] and Cheng [ㄷ] are consistent with the results of this study.

The prominent effect of the perceived usefulness on the continuance intention to use PACS system show that the users of this system are result-oriented and their incentive for use the system beyond its normal use level is dependent on the system's usefulness.

Managers should be aware that the most important issue in using a sophisticated system that has more features and capabilities is to estimate the efforts of users. This subject, about users' continuance intention to use shows the importance of the perceived usefulness. In order to achieve better results, managers should emphasize the userfriendly nature of the technology, in order to reduce the user's stress and become more prepared for continuance to use the information systems. So increasing the perceived usefulness through using the user-friendly systems will increase the willingness of users for continuance to use such systems.

The results of this study indicate that there is a significant relationship between perceived confirmation and perceived usefulness of the PACS system. These results are consistent with the results of Koo et al [28], Hsieh et al [27], Kim [23], Lee [24],

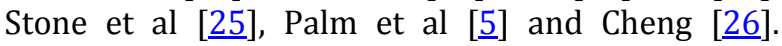
The results of the research showed that there is a significant relationship between perceived confirmation and PACS user support that is consistent with the results of Palm et al [ㅁ] .

The results of the research showed that there is a significant relationship between perceived confirmation and PACS system compatibility that is consistent with the results of Palm et al [ $\underline{5}]$.

Perceived confirmation is a strong and relevant determinant for each constructs i.e. perceived usefulness, user support, and compatibility of the PACS system and other information systems, which put the analysis of the needs and expectations of users in the center of success determinants of information systems and should be given special attention to the managers in the design and development process of these systems. User's expectation confirmation after a direct effect on perceived usefulness and user satisfaction indirectly affects the continuance intention to use and success of information systems.

The results of the present study confirm the significant relationship between user support and perceived usefulness of the PACS system, which is consistent with the results of Palm et al [ㄷ].

The results of the present study confirm the significant relationship between user support and satisfaction of the PACS system, which is consistent with the results of Palm et al [ㄷ].

As the results show, there is a significant relationship between compatibility and perceived usefulness of the PACS system, which is consistent with the results of Mailet et al [33], Palm et al [ㅁ] and $\mathrm{Hu}$ et al [15].

The results of this study confirm the significant relationship between compatibility and satisfaction of the PACS system, which is consistent with the results of Palm et al []ㅡ. In examining the results of the above relations, there is a significant relationship between the factors of user support and compatibility and each of the perceived usefulness and users' satisfaction factors. The user support and the compatibility of information systems is one of the technical factors of these systems that designers and managers must pay special attention to design, implementation and use of the system, because 
users' satisfaction is significantly affected by these factors (users support and compatibility).

Health information technology (HIT) managers must improve the capabilities of technical support, training, system security and information privacy, and the system's suitability to meet the needs and tasks of users in an easy manner, in information systems, and understand the needs that users consider to improve their capabilities and their specialized skills in using a system.

The results show that there is a significant relationship between the user quality and their satisfaction with the PACS system, which is in agreement with the results of the research, Monem et al [19]. The user quality is meant by those abilities that are associated with the acceptance and better use of the technology, such as information abilities and capabilities, interest, and motivation. The user quality is a strong stimulus to user satisfaction, which can affect the success or failure of the information systems.

\section{CONCLUSION}

The results of the research are an appropriate reference for health care institutions, information systems service providers and information systems developers to evaluate and improve the quality, usability and effectiveness of the systems. For information systems providers, it's essential to provide users support and compatibility to enhance system features and fit the needs of users. For health care institutions, allocating enough resources to provide appropriate training programs for systems can increase the ease of use of the system and reduce user resistance and thus lead to increased perceived usefulness, satisfaction, and continuance intention to use the information systems in users. Developers of the system by enhancing the technical characteristics of the systems to fit the system with the tasks of users can achieve more usability, perceived usefulness and satisfaction of users of the system, thus motivating users to continue to use systems.

The main limitation of this study was related to the collection of research data due to the difficulty of access to physicians during the study process; however, by designing an e-mail questionnaire and emailing this questionnaire, attempts were made to resolve this limitation.

\section{ACKNOWLEDGMENTS}

It is necessary to thank cooperation of the research deputy of the Shiraz University of Medical Sciences, the Nemazee Hospital's Clinical Research Center, the Student Research Committee of Faculty of Management and Information of Shiraz University of
Medical Sciences and PACS officials in Nemazee and Faghihi Hospitals of Shiraz. The present article is the result of a master's thesis under the project number 93-7176.

\section{AUTHOR'S CONTRIBUTION}

All the authors approved the final version of the manuscript.

\section{CONFLICTS OF INTEREST}

The authors declare no conflicts of interest regarding the publication of this study.

\section{FINANCIAL DISCLOSURE}

No financial interests related to the material of this manuscript have been declared.

\section{REFERENCES}

1. Bhattacherjee A. Understanding information systems continuance: An expectation-confirmation model. MIS Quarterly. 2001; 25(3): 351-70.

2. Ronis D, Yates J, Kirscht J. Attitudes, decisions, and habits as determinants of repeated behavior. in Attitude structure and function, Pratkanis AR, Breckler SJ, Greenwald AG (eds.). Hillsdale, NJ. Lawrence Erlbaum Associates; 1989.

3. Kim SS, Malhotra NK. A longitudinal model of continued IS use: an integrative view of four mechanisms underlying postadoption phenomena. Management Science. 2005; 51(5): 741-55.

4. Ahmadi M, Rezaei P, Shahmoradi L. EHR: Structure, content, evaluation. Tehran: Jafari; 2008.

5. Palm J, Dart T, Dupuis I, Leneveut L, Degoulet P. Clinical information system post-adoption evaluation at the Georges Pompidou university hospital. AMIA Annu Symp Proc. 2010: 582-6. PMID: 21347045 [PubMed]

6. Van de Velde R, Degoulet P. Clinical information systems: A component-based approach. New York: Springer-Verlag; 2003.

7. Abouzahra M, Tan J. The ICU-P model: Extending Delone and Mclean information systems success model to study clinicians` intention to continue using clinical decision support systems. 20th Americas Conference on Information Systems. Savanna; 2014.

8. Delone WH, McLean EH. The DeLone and McLean model of information systems success: A ten-year update. J Manag Inf Syst. 2003; 19(4): 9-30.

9. Holden RJ, Karsh BT. The technology acceptance model: Its past and its future in health care. J Biomed Inform. 2010; 43(1): 159-72. PMID: 19615467 DOI: 10.1016/j.jbi.2009.07.002 [PubMed]

10. Vankatesh V, Morris MG, Davis GB, Davis FD. User 
acceptance of information technology: Toward a unified view. MIS Quarterly. 2003; 27(3): 425-78.

11. Monem H, Hussin A, Sharifian R, Afrasiabi M. Neglected role of user in prominent IS models and framework. International Journal of Computer Applications. 2013; 72(1): 7-13.

12. van der Meijden MJ, Tange HJ, Troost J, Hasman A. Determinants of success of inpatient clinical information system: A literature review. J Am Med Inform Assoc. 2003; 10(3): 235-43. PMID: 12626373 DOI: $10.1197 /$ jamia.M1094 [PubMed]

13. Gagnon M, Desmartis M, Labrecque M, Car J, Pagliari C, Pluye $\mathrm{P}$, et al. Systematic review of factors influencing the adoption of information and communication technologies by healthcare professionals. J Med Syst. 2012; 36(1): 241-77. PMID: $20703721 \quad$ DOI: $\quad 10.1007 / \mathrm{s} 10916-010-9473-4$ [PubMed]

14. Pynoo B, Devolder P, Voet T, Sijnave B, Gemmel P, Duyck W, et al. Assessing hospital physicians' acceptance of clinical information systems: A review of the relevant literature. Psychologica Belgica. 2013; 53(2): 15-31.

15. Chau PYK, Hu PJ. Examining a model of information technology acceptance by individual professionals: An exploratory study. Journal of Management Information Systems. 2002; 18(4): 191-229.

16. Dany F, Romer B. Understanding dr. no- A comprehensive model explaining physicians' acceptance of tele medical systems. AIS Electronic Library (AISeL). 2014

17. Rogers EM. The diffusion of innovation. $5^{\text {th }}$ ed., New York: The Free Press; 2003.

18. Davis FD. Perceived usefulness, perceived ease of use, and user acceptance of information technology. MIS Quarterly. 1989; 13(3): 319-39.

19. Monem H, Afrasiabi M, Rezvan P, AbediDehkordi S. The impact of user quality and information quality on the IS success in healthcare context. J Basic Appl Sci Res. 2013; 3(10): 40-51.

20. Wang YS. Assessing e-commerce systems success: A respecification and validation of the DeLone and McLean model of IS success. Info Systems J. 2008; 18(5): 529-57.

21. Tabibi SJ, Farhangi AA, Nasiripour AA, Baradaran Kazemzadeh R, Ebrahimi P. The effect of supervisors and work group on hospital information system acceptance model. Journal of Health Management. 2012; 50(15): 52-64.

22. Hadji B, Dupuis I, Leneveut L, Heudes D, Wagner JF, Degoulet P. Determinants of continuance intention in a post-adoption satisfaction evaluation of a clinical information system. Stud Health Technol Inform. 2014; 205: 990-4. PMID: 25160336 [PubMed]

23. Kim B. An empirical investigation of mobile data service continuance: Incorporating the theory of planned behavior into the expectation-confirmation model. Expert Systems with Applications. 2010; 37(10): 7033-9.
24. Lee MC. Explaining and predicting users' continuance intention toward e-learning: An extension of the expectation-confirmation model. Computers \& Education. 2010; 54(2): 506-16.

25. Stone RW, Baker-Eveleth L. Students' expectation, confirmation, and continuance intention to use electronic textbooks. Computers in Human Behavior. 2013; 29(3): 984-90.

26. Cheng YM. What Drives Nurses' Blended e-Learning Continuance Intention? Journal of Educational Technology \& Society. 2014; 17(4): 203-15.

27. Hsieh JJ, Wang W. Explaining employees' extended use of complex information systems. European Journal of Information Systems. 2007; 16(3): 216-27.

28. Koo C, Wati Y, Park K, Lim MK. Website quality, expectation, confirmation, and end user satisfaction: The knowledge-intensive website of the Korean national cancer information center. J Med Internet Res. 2011; 13(4): 81-92. PMID: 22047810 DOI: 10.2196/jmir.1574 [PubMed]

29. Kulkarni UR, Ravindran S, Freeze R. A knowledge management success model: theoretical development and empirical validation. Journal of Management Information Systems. 2007; 23(3): 30947.

30. Landrum H, Prybutok VR. A service quality and success model for the information service industry. European Journal of Operational Research. 2004; 156(3): 628-42.

31. Tzeng WS, Kuo KM, Lin HW, Chen TY. A sociotechnical assessment of the success of picture archiving and communication systems: the radiology technologist's perspective. BMC Med Inform Decis Mak. 2013; 13: 109-23. PMID: 24053458 DOI: 10.1186/1472-6947-13-109 [PubMed]

32. Paré G, Lepanto L, Aubry D, Sicotte C. Toward a multidimensional assessment of picture archiving and communication system success. Int J Technol Assess Health Care. 2005; 21(4): 471-9. PMID: 16262970 DOI: $10.1017 /$ S0266462305050658 [PubMed]

33. Maillet E, Mathieu L, Sicotte C. Modeling factors explaining the acceptance, actual use and satisfaction of nurses using an Electronic Patient Record in acute care settings: an extension of the UTAUT. Int J Med Inform. 2015; 84(1): 36-47. PMID: 25288192 DOI: 10.1016/j.ijmedinf.2014.09.004 [PubMed] 